\title{
A New Approach in Recycling Waste Foundry Sand for the Preparation of Porous Silicon Powder
}

\author{
Rongfu Xu*, Yueya Shi, Changhou Li, Yong Xu \\ School of Materials Science and Engineering, Shandong Jianzhu University, Ji'nan 250101, Shandong, \\ China \\ *E-mail: $\underline{x r f 168 @ 163 . c o m}$
}

doi: $10.20964 / 2020.08 .32$

Received: 1 April 2020 / Accepted: 20 May 2020 / Published: 10 July 2020

\begin{abstract}
Disposal of waste foundry sand is still one of the most critical challenges faced by the foundry industry. The recycling and reusing of waste foundry sand not only lead to a saving of naturally abundant sand sources but also enhance the sustainability of environmental protection. A new approach in recycling waste foundry sand is introduced in the paper. Based on this approach, porous silicon powder is scalably fabricated, employing magnesiothermic reduction. In the initial one cycle, the capacities of the charge and discharge are $2210 \mathrm{mAh} / \mathrm{g}$ and $1602 \mathrm{mAh} / \mathrm{g}$, respectively. The coulombic efficiency of the asprepared porous silicon is about $72 \%$. The as-prepared porous silicon is considered as the potential material for the preparation of silicon-based anodes in high energy Li-ion batteries.
\end{abstract}

Keywords: waste foundry sand; porous silicon; magnesiothermic reduction; Li-ion battery

\section{FULL TEXT}

(C) 2020 The Authors. Published by ESG (www.electrochemsci.org). This article is an open access article distributed under the terms and conditions of the Creative Commons Attribution license (http://creativecommons.org/licenses/by/4.0/). 